\section{Worldwide news} and comment

February 2015 marked 10 years since the World Health Organization Framework Convention on Tobacco Control (FCTC) entered into force. While enormous progress has been made in curtailing the epidemic, the epicentre continues to be in countries that can least afford the devastating health, social and economic costs. Despite the legal framework provided by the FCTC to stymie the activities of the industry and protect public policy from its interests, the industry continues its attempts to obstruct effective measures, either through cultivating direct relationships with government officials or resorting to legal mechanisms to intimidate governments. In this issue, we provide an overview from the World Conference on Tobacco or Health (WCTOH), held in Abu Dhabi from 17-21 March. A significant announcement at WCTOH was the creation of an anti tobacco litigation fund, supported by Bloomberg Philanthropies and the Bill and Melinda Gates Foundation, to combat tobacco industry attempts to weaken tobacco control through legal challenges. We also look at recent attempts by the tobacco industry, supported by the British High Commissioner, in Pakistan to reverse legislation to increase the size of graphic health warnings, and two recent reports from Bangladesh on child labour and tobacco cultivation. On a brighter note, the Indian state of Punjab has recently banned loose tobacco sales, a move that may pave the way for stronger legislation elsewhere in India.

\section{TH WORLD CONFERENCE: FOCUS ON THE TOBACCO INDUSTRY}

The 16th World Conference on Tobacco or Health (WCTOH) was held in Abu Dhabi from March 17-21 2015, the first time it has been held in the Middle East. While this did not come without challenges (approximately 60 delegates, the majority from Bangladesh, were denied visas - see http:// blogs.bmj.com/tc/2015/03/17/15 th-worldconference-on-tobacco-or-health-regionaldelegates-refused-visas/), the conference was attended by 2,184 delegates from over 100 countries. In the opening plenary,

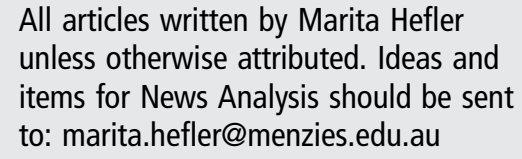
unless otherwise attributed. Ideas and items for News Analysis should be sent to: marita.hefler@menzies.edu.au

Dr Margaret Chan, Director General of the World Health Organization (WHO), rallied delegates to "keep the battle lines fresh and vigorous", setting the tone for a program that focused on curtailing the tobacco industry. Despite many successes, delegates were sobered by the record profits recorded by a number of tobacco companies since the 15 th WCTOH in 2012, notably in low income countries.

It is 10 years since the WHO FCTC came into force. So where are we now? Of the 178 countries with available data, about two thirds (125) show declining prevalence, but fewer than one in five (37) countries are on track to meet a $30 \%$ reduction by 2025 . Country-specific surveillance shows 45 countries have comprehensive smoke free policies, 21 have adequate cessation support, 30 have graphic warning labels ( $>50 \%$ of pack), 24 have total advertising \& promotion bans, and 32 have adequate taxation ( $75 \%$ of retail price). Day one of the scientific program focussed on growing evidence of the role of MPOWER, the technical package of technical measures and resources to achieve demand reduction provisions of the FCTC (Monitor tobacco use and prevention policies; Protect people from tobacco smoke, Offer help to quit tobacco use, Warn about the dangers of tobacco, Enforce bans on tobacco advertising, promotion and sponsorship, Raise taxes on tobacco).

The conference theme was 'Tobacco and Non-Communicable Diseases' (NCDs). It was refreshing to be reminded of the importance to think beyond tobacco, and hear shared learnings from countering food, beverage and alcohol marketing.
Delegates were urged to consider strategies that shift responsibility from the individual to industry and government, including product regulation, hard-hitting and sustained campaigns that raise public awareness, and advertising, promotion and sponsorship bans. Underpinning discussions was an awareness that funding available for preventing cardiovascular and other non-communicable diseases is in no way reflective of the scale of the NCD epidemic. Delegates heard about progress toward the World Health Assembly target to reduce tobacco use by $30 \%$ as part of the $25 \times 25$ global target of a $25 \%$ reduction in NCD deaths by 2025 , and advocacy efforts to integrate the FCTC with the UN Sustainable Development Goals (SDGs).

The social, economic and environmental impacts of the tobacco industry were also acknowledged: issues such as food and water insecurity, air pollution, deforestation and pesticide use, as well as trade, farming and poverty. Delegates were urged to speak out against these tobacco-related inequalities. A number of symposia featured the heavy burden on low and middle income countries, with a particular focus on 'best buy' tobacco control strategies.

Attention was also drawn to many countries failing to provide adequate financial resources to tackle implementation of the FCTC (including high income countries), and the importance of keeping tobacco control efforts free from industry funding and influence. At a national level, delegates heard of the importance of strengthening primary health care systems, improving alliances, and advancing the role of these systems as agents for social change. The importance of civil society was also

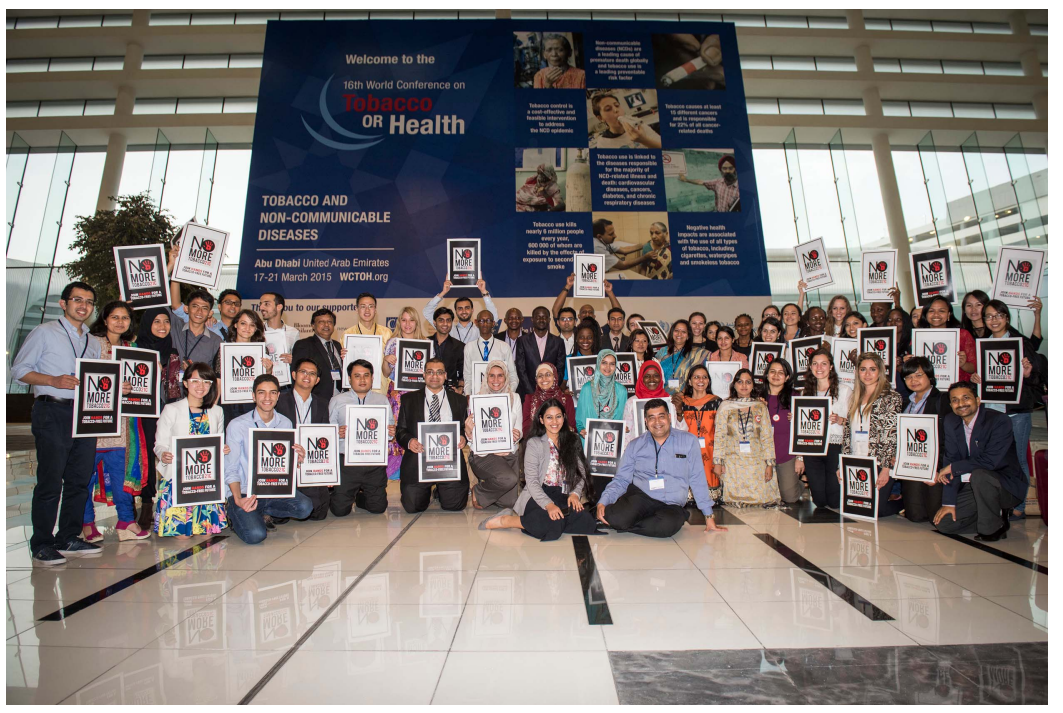

Youth delegates and the campaign for "No More Tobacco in the 21st Century" (\#NMT21C on Twitter). Photo Credit: WCTOH.SMUGMUG.COM. 


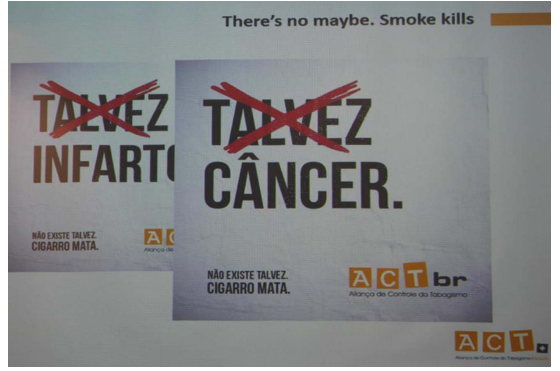

A subversion of Marlboro's Maybe Campaign. Photo credit: Laura Graen.

acknowledged, and delegates were encouraged to extend their partnerships and role as tobacco control advocates by including new champions for health reform.

Plain packaging was the focus of one plenary and a number of symposia. Nathan Smyth from the Australian Department of Health welcomed Ireland and the UK, which have both recently voted to introduce plain packaging, to "the greatest fight on Earth". There was much discussion of lessons learned from current legal battles against the tobacco industry, which aims to slow the diffusion of plain packs by tying up resources, increasing the costs, and countering the evidence base. It was heartening to see the growing number of nations who have plain packaging in their sights despite these battles.

Lack of an evidence base was a key argument the tobacco industry used to fight Australia when it became the first country to introduce plain packs in 2012. Professor Melanie Wakefield used the analogy of a train leaving the station, collecting evidence from stops en route to the destination of reduced prevalence.

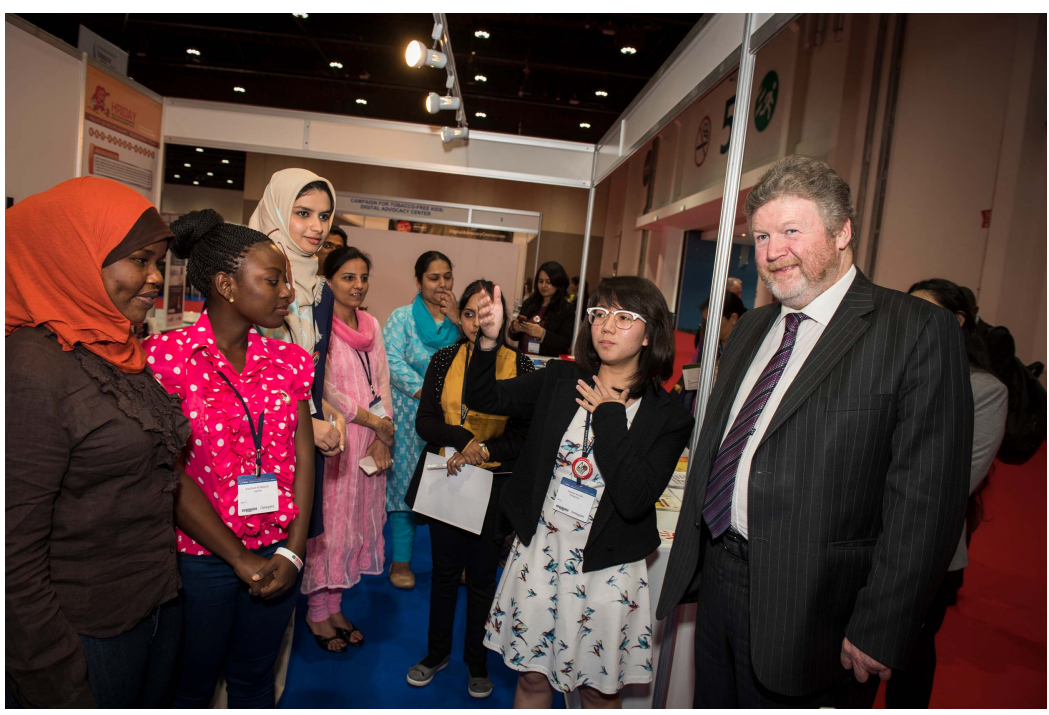

The Irish Health Minister James Reilly with WCTOH youth delegates. Ireland recently became the second country in the world to introduce plain packaging. Photo credit: WCTOH.SMUGMUG.COM.
Hot off the press of the April 2015 Tobacco Control supplement on plain packs, Professor Wakefield, Dr Michelle Scollo and other Australian researchers shared their 'en route' findings of the benefits of plain packs to reduce appeal and brand differentiation, focus attention on warning labels and reduce the ability to mislead consumers. Several presentations discussed the influence of pack shape and branding on consumer interpretations of attractiveness and harm, particularly for slim varieties, further highlighting the usefulness of standardised packaging. Delegates were also reminded of the synergistic effects of policies. Plain packs are not a magic bullet; rather they work with complementary policies such as total bans on other forms of tobacco industry advertising and promotion. (For more about the supplement and the implications of the research findings, see http://blogs.bmj. com/tc/2015/03/18/blockbuster-special-

issue-evaluation-of-the-australian-tobaccoplain-packaging-policy/).

Perhaps the most divisive debate was whether e-cigarettes should be viewed as a friend or foe of tobacco control. While the WHO urged caution, presenters in other symposia challenged the need for tight regulation, arguing this may stifle the emergence of potentially safer technologies. Experts appeared unanimous in their agreement that e-cigarettes produce metabolites known to cause disease such as lung cancer, emphysema, pulmonary fibrosis and cardiovascular events. However, the harm is greatly reduced compared to combustible cigarettes, and may be reduced further in new generations of e-cigarettes, particularly if new

technologies can eliminate heating altogether. Delegates learned that some youth are using e-cigarettes before smoking cigarettes; however, no strong evidence of a "gateway effect" was reported. Nonetheless, delegates and presenters voiced concern over the appeal of flavours, the need to ban sales to minors, and the need to monitor effects of vaping in public. Given that e-cigarettes are an increasingly popular form of cessation assistance, the issue of how to best regulate them presents a pressing challenge. Professor Ken Warner reminded delegates to keep the focus on evidence-based tobacco control, look to more enlightened regulation (that does not discourage innovation) and continue to reduce the attractiveness of combustible cigarettes.

After four days of stimulating science, the conference ended with a rousing vision from the youth pre-conference delegation on their campaign "No More Tobacco in the 21st Century" (\#NMT21C on Twitter), the prioritisation of which featured in one of the conference resolutions. Other conference resolutions centred on the FCTC: increasing signatories, achieving its recognition in the SDGs, and targets towards additional specific measures. There were also resolutions to treat tobacco uniquely in trade agreements, strengthen the Protocol to Eliminate Illicit Trade in Tobacco Products, and for a UN high level meeting to address the threat to humanity caused by tobacco. Interestingly, despite the discussions and presentations throughout the conference, other broad action on NCDs was not featured in the conference resolutions.

The conference closed with the announcement that South Africa had won the bid for the 17th WCTOH, the first time the conference will be hosted by an African nation. The challenge was set with the words of Nelson Mandela: "I have walked that long road to freedom. I have tried not to falter; I have made missteps along the way. But I have discovered the secret that after climbing a great hill, one only finds that there are many more hills to climb".

This article and related links are online at http://blogs.bmj.com/tc/2015/04/01/worldconference-on-tobacco-or-health-keepingthe-focus-on-the-tobacco-industry/

Anna Nicholson

Menzies School of Health Research, Australia Anna.Nicholson@menzies.edu.au

WORLD: BLOOMBERG \& GATES ANTI TOBACCO TRADE LITIGATION FUND

A highlight of the WCTOH was the launch of the Anti Tobacco Trade Litigation Fund, a new joint effort to combat the tobacco 
industry's use of international trade agreements to threaten and prevent countries from passing strong tobacco-control laws. Backed by Bloomberg Philanthropies and the Bill \& Melinda Gates Foundation, the new support for low and middle-income countries is the most recent element in a comprehensive strategy to reduce tobacco use globally.

In his announcement of the fund, Michael Bloomberg described the tremendous pressure placed on Uruguay, honoured at the Bloomberg awards, and currently under double legal assault from the tobacco industry. Bloomberg received a strong round of applause for noting that, while the country of just 3 million people could be forced to withdraw measures due to an inability to match the industry's funds, "We're here to make sure that doesn't happen."

Numerous countries have been threatened with legal action by the tobacco industry, a tactic that can lead to delays by governments in passing and implementing best-practice tobacco control laws. In addition to supporting countries facing suit before international trade tribunals, the Anti Tobacco Trade Litigation Fund includes technical assistance in drafting legislation to avoid legal challenges and potential trade disputes, support of global best practices in tobacco control and coordinated efforts to document industry wrongdoing, litigation support to low- and middle-income countries to help defend laws, communications support to educate and inform the public about the industry challenges to tobacco control policy and abuse of the trade system, assistance in accessing knowledgeable tobacco control experts and mobilising support among the global public health community to help countries defend against tobacco industry litigation and creation of a network of senior lawyers, experienced in trade litigation to support countries.

More detail about the fund, together with a list of Bloomberg award recipients, can be found at http://blogs.bmj.com/tc/2015/ 03/23/bloomberg-philanthropies-honorstobacco-control-organizations/

Stan Shatenstein

Smoking \& Tobacco Abstracts \& News Bulletin shatensteins@sympatico.ca

\section{PAKISTAN: BRITISH HIGH COMMISSIONER LOBBIES FOR TOBACCO INDUSTRY}

Tobacco industry pressure against government moves to introduce effective public policy to reduce tobacco use is to be expected. However, health and civil society groups in Pakistan and the UK were shocked at participation by the newly appointed British High Commissioner to Pakistan, Philip Barton, in a delegation headed by British American Tobacco to request the government of Pakistan to reverse its decision to implement $85 \%$ graphic health warnings.

The action was particularly surprising given that the UK has recently passed legislation for plain packaging of tobacco products-leading the way in Europe, and making it one of only three countries in the world to have done so. In addition, the UK published very comprehensive guidelines a year ago that explicitly prevent diplomats from engaging foreign governments on behalf of the tobacco industry, instead directing them to encourage and support robust tobacco control strategies, including large pictorial health warnings as the UK already has in place, in line with requirements of Article 5.3 of the FCTC.

Health and tobacco control organisations in both Pakistan and the UK condemned the involvement of $\mathrm{Mr}$ Barton in the meeting, and praised the Ministry of National Health Services, Regulations and Coordination (MNSRC) for resisting the pressure and maintaining the $85 \%$ legislation.

Khurram Hashmi, the National Coordinator Coalition for Tobacco Control Pakistan (CTC-Pak) said: "We applaud our government for not giving into the added pressure to retract the notification by the tobacco industry through the British High Commission. The government of Pakistan has taken a huge step towards the interest of health of its citizens and CTC-Pak on behalf of its 300 members would like to re-affirm its full support with the government for implementing new larger graphic health warnings on 30th March.”

More details and an international petition calling on the UK government to apologise can be found at https://www.change.org/p/ petition-to-uk-government-about-tobaccoindustry-lobbying-in-pakistan-publiclyapologise-for-the-breach-of-guidelines-andpromise-that-such-a-breach-will-not-happenagain

\section{BANGLADESH: STUDY SHOWS TOBACCO FARMING EXPANSION, CHILD LABOUR}

The Bangladesh non-government organisation (NGO) Progga Knowledge for Progress has released two reports which document the extent of child labour within the bidi industry and the aggressive expansion of tobacco cultivation in the country. Together, they paint a damning picture of negative health, social, education and economic impacts of the industry.

The first report Child labour in bidi industries of Bangladesh: An intensive investigation notes that in line with Section 32 of the UN Charter on Child Rights, Bangladesh has introduced a list of 38 hazardous jobs from which children are banned. Working in bidi or cigarette factories is fourth on the list. The problem of child labour in the Bangladesh tobacco and bidi industry is well documented; the study by the Tobacco Industry Watch BD team at PROGGA study provides a detailed picture of the extent of the problem and how it affects the children involved.

The study combined reviews of media reports with primary investigations, and found that while it is difficult to estimate with precision the total number of child labourers in the industry, most children employed are between four to 12 years old. In one district, it found there are 35 bidi factories employing about 40,000 people, approximately half of whom are children. Around 5000 of the children do not attend school at all, and many attend irregularly. Among those who do attend, many drop out around fifth grade due to access difficulties. In another district, which contains nearly $8 \%$ of the country's bidi factories, 21,000 labourers are engaged at the factories, $70 \%$ of whom are children between four and 14 years.

Children are engaged in all four stages of bidi production: preparing the shells (done in households), inserting chopped tobacco in the shells, closing the shell tops and preparing bidi packs. The hours are long: children usually work in the factories from 9 am to $12 \mathrm{pm}$, and then make bidi shells from $4 \mathrm{pm}$ to $9 \mathrm{pm}$ at their homes. The pay is low, with the average monthly income around TK420 (approximately US\$5.40) for 12 working days per month - an average of less than US50 cents per day.

Given the high levels of poverty, it is unsurprising that local communities reported children cannot get out of bidi processing once they are involved. Many children lack adequate nutrition, and they face a range of health problems including frequent fevers, coughs, headaches, abdominal problems, diarrhoea and muscle pain.

The report includes several case studies of children engaged in the industry from as young as five years old, usually to supplement the meagre and irregular earnings of their parents, sometimes subcontracted by middlemen employed by the factories. The children interviewed were typically underweight and small for their age, unwell and attended school irregularly or not at all, 


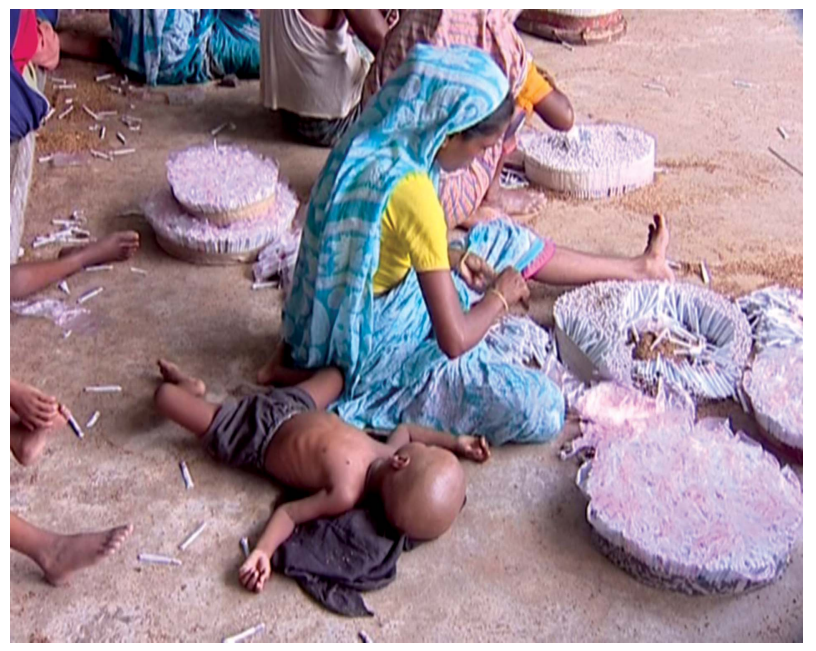

A photo of a young child sleeping on the floor of a bidi factory next to its mother. Low pay means whole family groups sometimes need to work together.

with at least one child interviewed working 12 hour days with her father.

The report also contains a description of working conditions and photos taken covertly within a factory. Accounts include the air being heavily polluted with tobacco powder and dust, production teams made up of family members, and children from as young as six months sleeping on the floor. Hot conditions with no fans inside mean that many workers wear only undershirts or no shirts to cope with temperatures of up to 39 degrees Celsius.

The second report, Aggressive tobacco farming in Bangladesh: Risks and responsibilities, details the need for Bangladesh to introduce supply reduction measures as part of its obligations under the FCTC, a significant gap in the current Bangladesh tobacco control law. In the absence of effective measures to control supply, the report details how the tobacco industry has expanded tobacco farming in recent years, with land that could be used for food production being used to grow tobacco.

From the 2012-2103 to 2013-2014 seasons, the land for tobacco cultivation increased from 70,000 hectares to 108,000 hectares. Overall in the last six years, tobacco leaf production has more than doubled, and according to the Bangladesh Food Ministry and the world Food \& Agriculture Organization, the country is losing an average of 69,000 hectares of arable land per year to tobacco cultivation. The rapid growth in land used for tobacco cultivation potentially represents a threat to food security: given that one hectare of land can produce 3.9 metric tonnes of rice, the 108,000 currently devoted to tobacco could have produced 421,2000 tonnes of rice. As is the case elsewhere, tobacco cultivation has other negative impacts in Bangladesh including deforestation to supply fuel for tobacco furnaces and loss of soil fertility due to significantly higher use of pesticides than would be required for rice growing.

The report provides a range of recommendations to address the challenges expanded tobacco cultivation poses for Bangladesh. These include government assistance to produce alternative crops, a policy to prevent tobacco industry interference and inducements to increase tobacco farming, a tobacco farming control policy, a national working group, hypothecating a health development surcharge to retraining and employment alternatives for tobacco farmers, stronger restrictions on deforestation and limiting arable land that can be used for tobacco farming.

Both reports can be obtained by contacting progga.bd@gmail.com or info@progga.org.

Tobacco industry watch team

PROGGA Knowledge for Progress, Bangladesh progga.bd@gmail.com

\section{INDIA: PUNJAB BANS SINGLE CIGARETTE SALES}

In January 2015, Punjab became the first state of India to ban sales of single cigarettes and loose smokeless tobacco. More than 100 billion cigarettes were smoked in India in 2012, and according to Euromonitor International India, 70\% of the cigarettes in India are sold loose. FCTC Article 16 on sales to or by minors states that countries "shall endeavor" to prohibit such sales, in order to reduce affordability for minors. India is a Party to the FCTC.

The Punjab Department of Health and Family Welfare found that selling loose tobacco and single cigarettes was a violation of section 7 of COTPA (Cigarettes and Other Tobacco Products, Prohibition of Advertisement and Regulation of Trade and Commerce, Production, Supply and Distribution Act, 2003), which says that every package of cigarettes or any other tobacco products sold, supplied or distributed must carry a specified pictorial warning.

Several strategies were used to implement and enforce the order, including a comprehensive media campaign. All Deputy Commissioners (administrative heads of districts) and Civil Surgeons (head of district health departments) held meetings with tobacco wholesalers to make them aware that selling loose tobacco and single cigarettes breaches Section 7 of COTPA. Violators are now being booked. The Principal Secretary, Health and Family Welfare issued the notification of the ban, and is regularly monitoring enforcement in monthly meetings with Civil Surgeons.

The decision is expected to help decrease tobacco consumption by reducing affordability of tobacco products, especially to low-income smokers and youth, who constitute the majority of loose tobacco product and single cigarette stick purchasers. A single cigarette costs about 10 rupees (16 cents) in the capital, New Delhi, compared with a pack of 20 that costs 190 rupees (US\$3). In addition, the law is expected to increase exposure to warning labels, which are not carried on loose tobacco sales.

The ban on sale of loose cigarettes and tobacco by the Government of Punjab opens the way for other states to follow suit, and may increase the age of initiation of tobacco use by making it unaffordable for children and youth.

Sonu Goel

Chandigarh Post Graduate Institute of Medical Education \& Research sonugoel007@yahoo.co.in

Rakesh Gupta Health \& Family Welfare, Punjab

Tob Control 2015;24:213-216.

doi:10.1136/tobaccocontrol-2015-052386 